\title{
Genome-wide DNA methylation pattern in a mouse model reveals two novel genes associated with Staphylococcus aureus mastitis
}

\author{
Di Wang ${ }^{1, a}$, Yiyuan Wei, ${ }^{1, a}$, Liangyu Shi', Muhammad Zahoor Khan', Lijun Fan', \\ Yachun Wang ${ }^{1}$, and Ying $\mathbf{Y u}^{1, *}$
}

\begin{abstract}
* Corresponding Author: Ying Yu Tel: +86-010-62734611, Fax: +86-10-62732439, E-mail: yuying@cau.edu.cn
\end{abstract}

'Key Laboratory of Agricultural Animal Genetics and Breeding, National Engineering Laboratory for Animal Breeding, College of Animal Science and Technology, China Agricultural University, Beijing 100193, China

a These two authors contribute equally to this work.

ORCID

Di Wang

https://orcid.org/0000-0002-2459-4742

Yiyuan Wei

https://orcid.org/0000-0001-6689-675X

Liangyu Shi

https://orcid.org/0000-0003-4236-3531

Muhammad Zahoor Khan

https://orcid.org/0000-0001-5890-2996 Lijun Fan

https://orcid.org/0000-0002-2837-9230

Yachun Wang

https://orcid.org/0000-0003-3629-2802

Ying Yu

https://orcid.org/0000-0002-4524-0791

Submitted Nov 15, 2018; Revised Dec 20, 2018; Accepted Mar 7, 2019
Objective: Staphylococcus aureus (S. aureus) is one of the major microorganisms responsible for subclinical mastitis in dairy cattle. The present study was designed with the aim to explore the DNA methylation patterns using the Fluorescence-labeled methylation-sensitive amplified polymorphism (F-MSAP) techniques in a S. aureus-infected mouse model.

Methods: A total of 12 out-bred Institute of Cancer Research female mice ranging from 12 to 13 weeks-old were selected to construct a mastitis model. F-MSAP analysis was carried out to detect fluctuations of DNA methylation between control group and S. aureus mastitis group.

Results: Visible changes were observed in white cell counts in milk, percentage of granulocytes, percentage of lymphocytes, $\mathrm{CD}^{+} / \mathrm{CD}^{+}$ratio $\left(\mathrm{CD} 4^{+} / \mathrm{CD} 8^{+}\right)$, and histopathology of mice pre- and post-challenge with $S$. aureus. These findings showed the suitability of the $S$. aureus-infected mouse model. A total of 369 fragments was amplified from udder tissue samples from the two groups (S. aureus-infected mastitis group and control group) using eight pairs of selective primers. Results indicated that the methylation level of mastitis mouse group was higher than that in the control group. In addition, NCK-associated protein 5 (Nckap5) and transposon MTD were identified to be differentially methylated through secondary polymerase chain reaction and sequencing in the mastitis group. These observations might play an important role in the development of S. aureus mastitis.

Conclusion: Collectively, our study suggests that the methylation modification in Nckap5 and transposon MTD might be considered as epigenetic markers in resistance to S. aureusinfected mastitis and provided a new insight into $S$. aureus mastitis research in dairy industry and public health.

Keywords: Staphylococcus aureus-infected Mouse Model; F-MSAP Method; DNA Methylation; Udder Tissue; Differentially Methylated Genes

\section{INTRODUCTION}

Bovine mastitis is considered as a serious problem to the dairy industry [1,2], which reduces the quantity and quality of milk as well as threatens public health [3]. It was responsible for more than $\$ 2$ billion annual losses to the US dairy sector [4] and about $\$ 35$ billion losses to the world [5]. The incidence of subclinical mastitis in modern dairy farms is much higher than clinical mastitis $(<5 \%)$ and normally around $26 \%$ to $68 \%$. Subclinical mastitis can be detected by increased milk somatic cell counts (SCC) [6], 200,000 to 500,000 of cells/mL in milk was considered as an indicator of subclinical mastitis in dairy cattle, while SCC in healthy mammary gland is less than 100,000 of cells $/ \mathrm{mL}$. The main reason for increased SCC in mammary glands is the invasion of pathogens, nowadays, the major pathogen responsible for bovine subclinical mastitis is Staphylococcus aureus (S. aureus) [7]. 
Inflammation progress of udder tissue is controlled by genetic and epigenetic factors as well as pathogens. DNA methylation, one of the main epigenetic modification mechanisms, plays an important role in gene expression $[8,9]$. DNA methylation around the signal transducer and activator of transcription 5-binding enhancer in the casein alpha S1 promoter was shown to be associated with shutdown of aS1casein synthesis during acute mastitis [10]. Our previous research revealed that bovine mastitis enhances the level of methylation in the promoter of CD4 molecule (CD4) and alternatively decreases the expression of $\mathrm{CD} 4$ by blocking the transcription factor binding [11]. Chang et al [12] suggested toll-like receptor 4 promoter was linked to a recognized mechanism of epigenetic regulation of gene expression in Escherichia coli mastitis. In 2016, Song et al [13] found three genes (macrophage stimulating 1 , neuregulin 1 , and $\mathrm{N}$-acetyltransferase 9) with DNA methylation changes can serve as potential biomarkers in $S$. aureus subclinical mastitis. These studies showed that epigenetics have a key role in bovine mastitis and should be evolved in the strategies of mastitis control. However bovine mammary gland tissue is difficult to obtain because of injury to animals and economic losses, thus searches for an animal model have been carried out [14].

The laboratory mouse is widely used for scientific research in epigenetics and disease progress. There is little information in the cited literature about whole genome DNA methylation changes in a $S$. aureus-induced mastitis mouse model. Methylation-sensitive amplified polymorphism (MSAP) analysis depends on two different DNA methylation-sensitive restriction isoschizomers (Hpa II and Msp I) for the same restriction site (CCGG) and has been extensively used to explore genomic DNA methylation levels and patterns because of its reliability, sensitivity and convenient operation [15]. Fluorescence-labeled MSAP (F-MSAP) which is based on fluorescently labeled primers is more sensitive, safer and effective than the original MSAP [16]. To determine the DNA methylation changeability in udder tissue of $S$. aureus mastitis, in the current study, genomic DNA methylation variation and related genes were investigated in a mouse model using the F-MSAP method.

\section{MATERIALS AND METHODS}

\section{Care and use of animals}

All protocols and procedures for the experimental mice were reviewed and approved by the Institutional Animal Care and Use Committee at China Agricultural University, China (Permission number: DK996). All the experiments were performed in strict accordance with the regulations and guidelines established by this committee. Before tissue sampling, the mice were euthanized by cervical dislocation. All efforts were made to minimize their suffering.

\section{Sample selection and size}

A total of 12 out-bred Institute of Cancer Research female mice ranging from 12-13 weeks-old were selected to develop a mastitis model. S. aureus was collected from fresh milk of mastitis dairy cattle. Bacteriological culture of milk samples was performed according to National Mastitis Council standards [17]. A volume of $3 \mathrm{~mL}$ milk was mixed into trypticase soy broth containing $7.5 \% \mathrm{NaCl}$ and cultured at $37^{\circ} \mathrm{C}$ for 18-24 h. The $S$. aureus was confirmed by specific halo and transparent ring around the colony. Thermonuclease $(n u c)$ gene has been used for rapid identification of $S$. aureus, thus polymerase chain reaction (PCR) for amplification of nuc gene was performed to identify $S$. aureus to double check $[18,19]$. The primers of nuc gene are as follows: F: 5'-GCGA TTGATGGTGATACGGTT-3', R: 5'-AGCCAAGCCTTGA CGAACTAAAGC-3'. A $50 \mu \mathrm{L}$ of the $S$. aureus culture $\left(5 \times 10^{6}\right.$ colony-forming unit) was carefully inoculated into the fourth abdominal pair teats (left and right) of the mammary gland of six mice with a blunt head capillary glass tube to induce $S$. aureus mastitis. Simultaneously, six healthy control mice (C1C6) were inoculated with sterile, pyrogen-free saline.

\section{Physiological and biochemical indicators detection}

Body temperature test: The temperature of the rectum of the mice was measured at 5 time points per day, i.e., 0 h, $6 \mathrm{~h}, 12$ $\mathrm{h}, 18 \mathrm{~h}$, and $24 \mathrm{~h}$ using an electronic thermometer.

Paraffin section and hematoxylin-eosin section: The 4th pair of udder tissue was collected after the mice were humanely killed through cervical dislocation. Then the tissues were paraffin embedded and sectioned, and finally hematoxylineosin (HE) staining was performed.

Milk white cell count: A total of $10 \mu \mathrm{L}$ of milk was evenly spread onto the slides. Then after NEWMANS staining, the number of white cells in 10 fields was counted through microscope, and the average value was taken as the result.

Complete blood count: A total of $1 \mathrm{~mL}$ blood was collected from orbital sinus and complete blood count (CBC) (including granulocytes [GRN] and percentage of granulocytes [GRN $\%$ ], lymphocytes [LYM] and percentage of lymphocytes [LYM \%]) was conducted by Xiyuan Hospital CACMS, Haidian, Beijing, China.

$C D 4^{+} / C D 8^{+}$ratio: A total of $200 \mu \mathrm{L}$ fresh peripheral blood was collected from orbital sinus, and the cell counts of $\mathrm{T}$ helper/inducer lymphocytes $\left(\mathrm{CD}^{+}\right)$and T suppressor/cytotoxic lymphocytes $\left(\mathrm{CD}^{+}\right)$were measured by flow cytometry (conducted by Xiyuan Hospital CACMS, China; antibody information: anti-CD4 $4^{+} \mathrm{CD} 8$ antibody [EDU-2+733], Abcam, Shanghai, China). The $\mathrm{CD} 4^{+} / \mathrm{CD}^{+}$ratio is the ratio of T helper cells (with the surface marker CD4) to cytotoxic T cells (with the surface marker CD8). 


\section{Genomic DNA isolation from udder tissue}

Related physiological and biochemical indicators as well as udder tissue samples were obtained at $24 \mathrm{~h}$ after intra-mammary infection (IMI) with S. aureus. The mice were euthanized using cervical dislocation method. The skin surface of the fourth pair of mammary glands was washed with $75 \%$ ethanol and dried; consequently, the udder tissues were sampled quickly and carefully. The collected udder tissues were used for DNA extraction with Wizard Genomic DNA Purification Kit (Promega, Madison, Madison, USA) and the genomic DNA was run in $1 \times$ Tris-boric acid-ethylene diamine tetraacetic acid on $1 \%$ agarose gel electrophoresis to check its integrity.

\section{DNA digestion, ligation and amplification}

DNA digestion: DNA samples from both the mouse groups were digested with two different isoschizomer systems $(E c o R$ I/Hpa II and EcoR I/Msp I), respectively, in a water bath at $37^{\circ} \mathrm{C}$ for overnight. The EcoR I/Msp I digestion system was performed in a reaction including 500 to $800 \mathrm{ng}$ genomic DNA, $1 \mu \mathrm{L}$ EcoR I, $1 \mu \mathrm{L}$ Msp I, $4 \mu \mathrm{L} 10 \times \mathrm{B} 4$ buffer and $13 \mu \mathrm{L}$ $\mathrm{ddH}_{2} \mathrm{O}$. EcoR I/Hpa II digestion was performed in a reaction containing $1 \mu \mathrm{L}$ genomic DNA, $1 \mu \mathrm{L}$ EcoR I, $2 \mu \mathrm{L}$ Msp I, $4 \mu \mathrm{L}$ $10 \times \mathrm{B} 1$ buffer and $12 \mu \mathrm{L}$ deionized water.

Ligation: The ligation was then performed in a final volume of $30 \mu \mathrm{L}$ including $12.5 \mu \mathrm{L}$ enzyme-digested products, $1 \mu \mathrm{L}$ (10 pmol) EcoR I adapter, $1 \mu \mathrm{L}$ (10 pmol) Hpa II/Msp I adapters, $0.5 \mu \mathrm{L}$ T4 ligase, $4 \mu \mathrm{L} 10 \times \mathrm{T} 4$ buffer and $9 \mu \mathrm{LddH}_{2} \mathrm{O}$ and incubated at $16^{\circ} \mathrm{C}$ overnight and then inactivated at $65^{\circ} \mathrm{C}$ for 10 minutes.

Pre-amplification polymerase chain reaction: Four microliter of the above ligation product was pre-amplified as a template in a final volume of $20 \mu \mathrm{L}$ contained $42 \mathrm{ng} \mathrm{H}-\mathrm{M}+1$ primer, $41 \mathrm{ng} \mathrm{E}+1$ primer, $0.1 \mu \mathrm{L}$ Ex Taq polymerase, $1.6 \mu \mathrm{L} \mathrm{dNTP}$, $1.2 \mu \mathrm{L} \mathrm{MgCl}_{2}, 2 \mu \mathrm{L} 10 \times \mathrm{Ex}$ buffer and $9.5 \mu \mathrm{L}$ deionized water. The PCR conditions were as follows: $94^{\circ} \mathrm{C}$ for $5 \mathrm{~min} ; 30$ cycles of $94^{\circ} \mathrm{C}$ for the $30 \mathrm{~s}, 56^{\circ} \mathrm{C}$ for $1 \mathrm{~min}$, and $72^{\circ} \mathrm{C}$ for $1 \mathrm{~min}$; and a final extension at $72^{\circ} \mathrm{C}$ for $7 \mathrm{~min}$.

Selective amplification polymerase chain reaction: Selective amplification PCR was performed in a final volume of $20 \mu \mathrm{L}$ including $4 \mu \mathrm{L}$ pre-amplified products, $41 \mathrm{ng} \mathrm{H}-\mathrm{M}+3$ primer, $12 \mathrm{ng}$ E+3 primer, $0.1 \mu \mathrm{L}$ Ex Taq polymerase, $1.6 \mu \mathrm{L}$ dNTP mixture, $1.2 \mu \mathrm{L} \mathrm{MgCl} 2,2 \mu \mathrm{L}$ 10×Ex Taq buffer, and $\mathrm{ddH}_{2} \mathrm{O}$. The PCR amplification reactions were performed using touchdown cycles under the following conditions: $94^{\circ} \mathrm{C}$ for $5 \mathrm{~min}$; 13 touch-down cycles of $94^{\circ} \mathrm{C}$ for $30 \mathrm{~s}, 65^{\circ} \mathrm{C}$ (subsequently reduced each cycle by $0.7^{\circ} \mathrm{C}$ ) for $30 \mathrm{~s}$ and $72^{\circ} \mathrm{C}$ for $15 \mathrm{~s} ; 23$ continued cycles of $94^{\circ} \mathrm{C}$ for $30 \mathrm{~s}, 56^{\circ} \mathrm{C}$ for $30 \mathrm{~s}$ and $72^{\circ} \mathrm{C}$ for $15 \mathrm{~s}$; and extension at $72^{\circ} \mathrm{C}$ for $7 \mathrm{~min}$. The adapters and primers used in the present study are summarized in Table 1.

\section{Silver staining}

Table 1. The adapters and primers used in Fluorescence-labeled methylationsensitive amplified polymorphism

\begin{tabular}{|c|c|c|}
\hline Name & & $5^{\prime} \rightarrow 3^{\prime}$ Sequence \\
\hline \multirow[t]{4}{*}{ Adapters } & Hpa II/Msp I adapters & GACGATGTCTAGAA \\
\hline & & CGTTCTAGACTCATC \\
\hline & Eco $R$ I adapters & CTCGTAGACTGCGTACC \\
\hline & & AATTGGTACGCAGTCTAC \\
\hline \multirow[t]{2}{*}{ Pre-selective primers } & Hpa II/Msp I+T & GATGAGTCTAGAACGG-T \\
\hline & $E C O R I+A$ & GACTGCGTACCAATTC-A \\
\hline \multirow[t]{6}{*}{ Selective-primers } & Hpa II/Msp I+TAC & GATGAGTCTAGAACGG-TAC \\
\hline & Hpa II/Msp I+TAG & GATGAGTCTAGAACGG-TAG \\
\hline & ECOR I+AAC & GACTGCGTACCAATTC-AAC \\
\hline & ECOR I+ATG & GACTGCGTACCAATTC-ATG \\
\hline & ECOR I+AAG & GACTGCGTACCAATTC-AAG \\
\hline & ECOR I+ATC & GACTGCGTACCAATTC-ATC \\
\hline
\end{tabular}

Note: There are eight pairs of combined selective-primers as below: Primer 1: F: GATGAGTCTAGAACGG-TAC; R: GACTGCGTACCAATTC-AAC Primer 2: F: GATGAGTCTAGAACGG-TAC; R: GACTGCGTACCAATTC-ATG Primer 3: F: GATGAGTCTAGAACGG-TAC; R: GACTGCGTACCAATTC-AAG Primer 4: F: GATGAGTCTAGAACGG-TAC; R: GACTGCGTACCAATTC-ATC Primer 5: F: GATGAGTCTAGAACGG-TAG; R: GACTGCGTACCAATTC-AAC Primer 6: F: GATGAGTCTAGAACGG-TAG; R: GACTGCGTACCAATTC-ATG Primer 7: F: GATGAGTCTAGAACGG-TAG; R: GACTGCGTACCAATTC-AAG Primer 8: F: GATGAGTCTAGAACGG-TAG; R: GACTGCGTACCAATTC-ATC

After the selective amplification PCR, the products were loaded into polyacrylamide gel electrophoresis (PAGE) and then silver staining was performed. The silver staining steps are as following.

Firstly, the PAGE gel was fixed in a solution of $75 \%$ ethanol for 15 to $30 \mathrm{~min}$ with gentle shaking. Then washed the gel three times using deionized water. Later, a total of $200 \mathrm{~mL}$ $0.5 \% \mathrm{AgNO}_{3}$ solution was added, incubating the gel $30 \mathrm{~min}$ at room temperature with gentle shaking (100 to $120 \mathrm{rpm}$ ). After incubation, the $\mathrm{AgNO}_{3}$ solution was discarded and both sides of the gel were washed for $20 \mathrm{~s}$ using deionized water. Next, a total of $200 \mathrm{~mL}$ freshly made aqueous solution of $7.5 \%$ sodium carbonate was added and with gentle shaking for $5 \mathrm{~min}$. Afterwards, a total of $1.25 \mathrm{~mL}$ solution of $40 \%$ formaldehyde was added, then the gel was incubated at room temperature with gentle shaking. After washing the gel carefully, stained bands appeared within a few minutes. The incubation continued until all desired bands appeared. Finally, the reaction was quenched by washing the gel in $1 \%$ acetic acid for a few minutes and then the gel washed several times with deionized water (10 min per wash).

\section{Fluorescence-labeled methylation-sensitive amplified polymorphism analysis}

Based on the silver staining results, four pairs of selective-primers with more different bands were selected to be fluorescent labeled (FAM-labeled) to perform F-MSAP analysis.

In the F-MSAP technique, the digestion of DNA was performed with different methylation sensitive isoschizomers 
(Hpa II and Msp I) as well as an internal control restriction enzyme (EcoR I) as shown in (Figure $1 \mathrm{~A}, 1 \mathrm{~B})$. The enzymedigestion products were then ligated to adapters and preamplification and selective amplification with FAM-labeled primers was performed [16]. The amplified products with FAM-labeled primers were detected through the ABI3730 platform. Finally, the F-MSAP fragments were analyzed using GeneMarker V1.65 by detecting fluorescent signals of different intensity and locations. Four types of bands were detected. $t$-test and chi-square test were used in significance analysis of methylation levels between the two experimental groups. The level of statistical significance was set at $\mathrm{p}<0.05$.

Ultimately, a total of 20 different bands were excised from polyacrylamide gels after silver staining, followed with secondary PCR and sequencing to identify the differentially methylated genes.

\section{RESULTS}

\section{Physiological differences between S. aureus infected mice and healthy controls}

The $S$. aureus strain used to infect the mice was confirmed by specific PCR amplification of the nuc gene (Supplementary Figure S1). In order to get uniformity and standard S. aureusinfected mouse model, several parameters were checked preand post-challenge with $S$. aureus (Figure 2A).

Before the S. aureus attack, there was no difference for the body temperatures between $\mathrm{C}$ group and SM group (C: control group; SM: S. aureus induced mastitis group); however, a significant rise of body temperature was observed in SM group compared to the controls after $24 \mathrm{~h} \mathrm{IMI} \mathrm{(Figure} \mathrm{2B).}$ Furthermore, white cell counts in milk and GRN \% were also increased (Figure 2C, 2E), while the LYM \%, as well as $\mathrm{CD}_{4}^{+}$/ $\mathrm{CD}^{+}$, were significantly decreased in SM group after IMI (Figure 2D, 2F). For further confirmation, paraffin sectioning and HE staining were carried out to check whether there was any abnormality in tissue, which showed inflammatory cells infiltration, the space between the cells becoming wider and with sloughing off of epithelial cells in SM group (Figure 2G). These findings indicated that the mouse model was launched successfully and provided a foundation for the subsequent studies (Figure 2).

\section{Four cleavage patterns of DNA methylation}

The cleavage patterns were defined and shown in four types according to the methylation sensitivity of the isoschizomers as mentioned in Figure 1C and 1D. The PAGE gel electrophoresis indicated four methylation types shown in Figure 1E. Type I bands (un-methylated) appeared in both EcoR I/ $M s p$ I and EcoR I/Hpa II digestion. Type II bands (inner methylated of double stranded sequence) appeared only in EcoR I/ Msp I digestion but not digested in the EcoR I/Msp I. Type III bands (semi-methylated, outer methylated of single stranded sequence) obtained in EcoR I/Hpa II digestion but could not be digested in EcoR I/Msp I. Type IV (outer methylated of double stranded sequence) represents the absence of bands in both enzyme combinations.

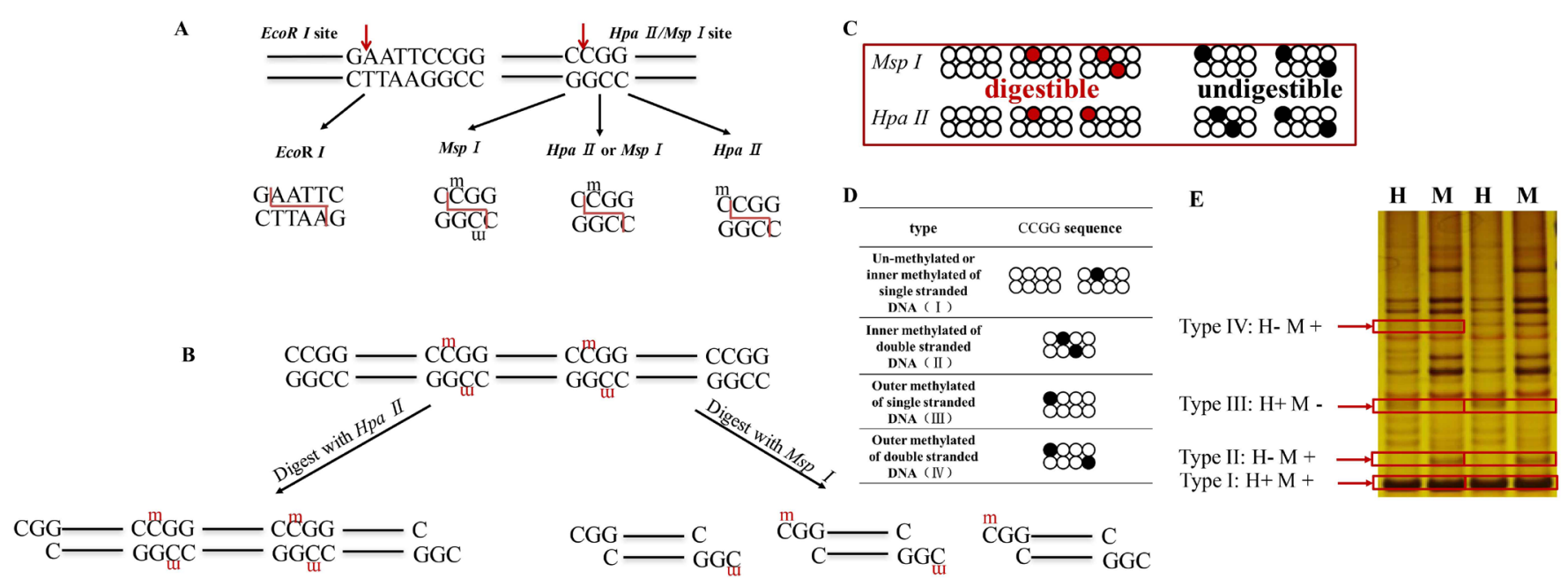

Figure 1. Schematic representation of the two isoschizomers and four DNA methylation patterns. (A) Hpa II is digestible in inner and outer methylated of single stranded CCGG suequece; Msp I is digestible in inner methylated of single and double stranded sequence; EcoR I is an internal control restriction enzyme which recognizes the GAATTC sequence. (B) An example DNA sequence is digested with isoschizomers (Hpa II and Msp I) and divided into different fragments. (C) Activity of the two isoschizomers. Msp I can recognize inner methylation of single and double stranded CCGG sequence, but cannot recognize outer methylation of single and double stranded CCGG sequence. Hpa II can recognize inner and outer methylation of single stranded CCGG sequence, but cannot recognize inner and outer methylation of double stranded CCGG sequence. The digested sites were shown in red circle and undigested sites are shown in black circle. (D) Illustration of four DNA methylation pattern types. (E) The agarose gel electrophoreses (silver stain) indicate four methylation types. Line M: a system of EcoR I/Msp I; line H: a system of EcoR I/Hpa II; H+: Hpa II digested; H-: Hpa II undigested; M+: Msp I digested; M-: Msp I undigested. 
A

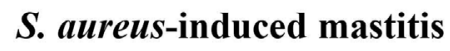

Healthy control

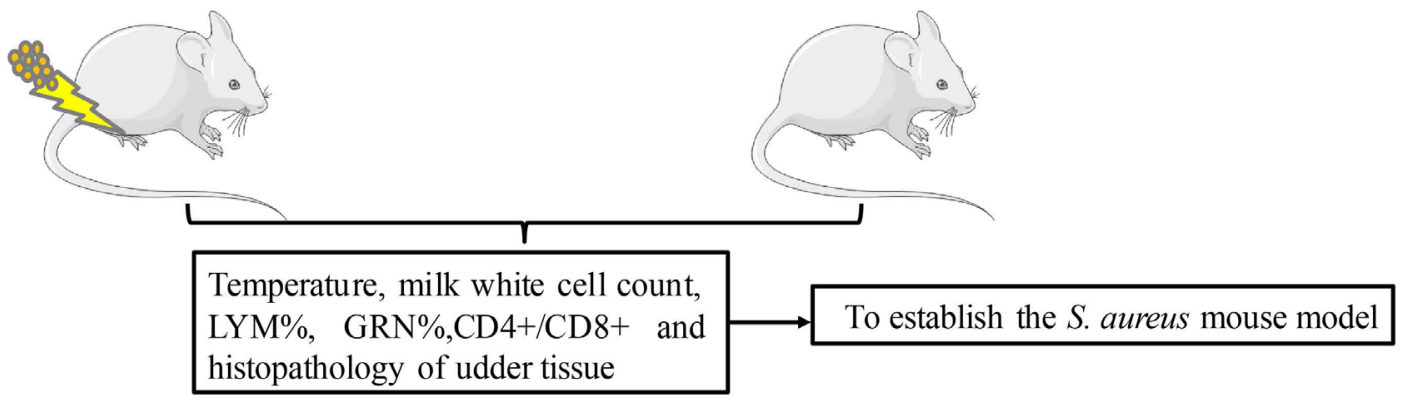

B

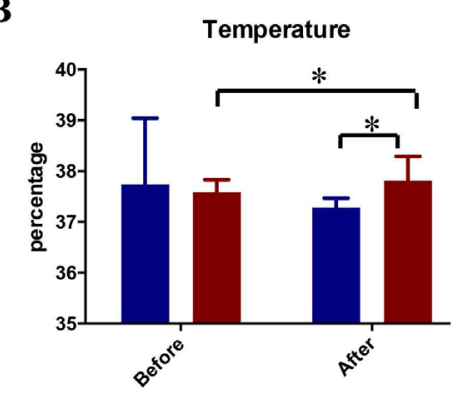

$\mathbf{E}$

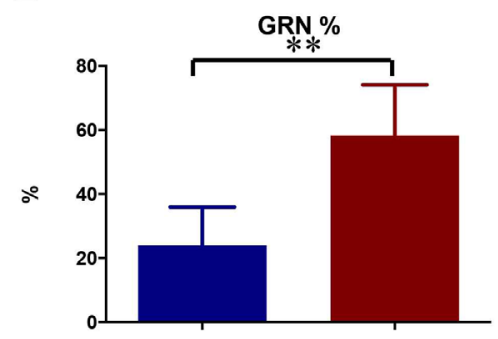

C
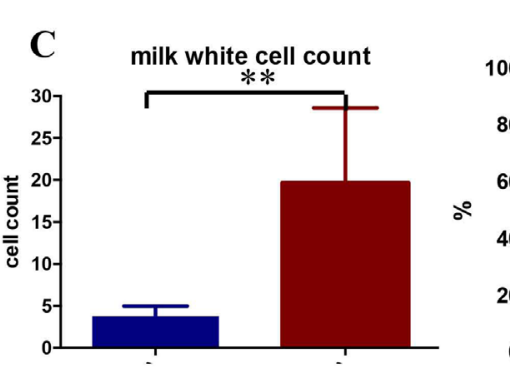

D LYM \%

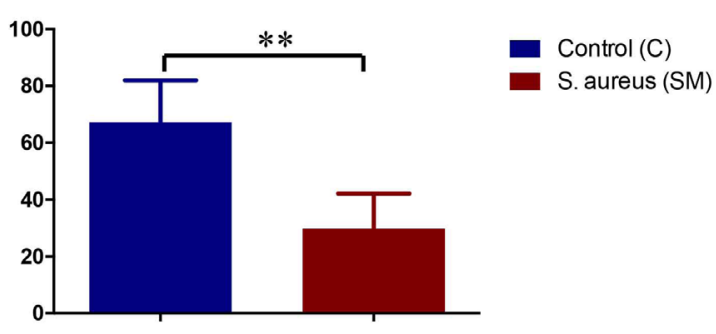

G

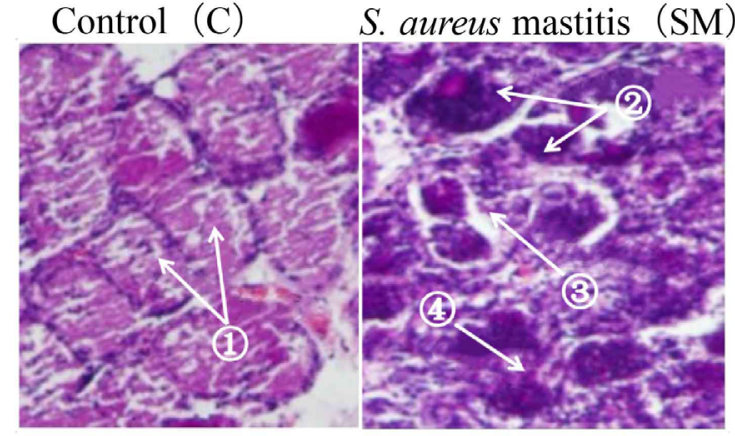

Figure 2. Differences of the physiological and biochemical indexes between the two groups. (A) Schematic sketch of establishing Staphylococcus aureus (S. aureus)induced mastitis mouse model. (B) Temperature difference between healthy control and S. aureus mastitis; ${ }^{*} p<0.05$. (C) Milk white cell counts; ${ }^{* *} p<0.01$. (D) LYM \%: percentage of lymphocytes; ${ }^{* *} p<0.01$. (E) GRN \%: percentage of granulocytes; ${ }^{* *} p<0.01$. (F) $\mathrm{CD}^{+} / \mathrm{CD}^{+}$: $\mathrm{CD4}^{+} / \mathrm{CD} 8^{+}$ratio; ${ }^{* *} \mathrm{p}<0.01$. (G) Udder tissue slices: (1) Alveolus are complete in HC group, (2) Inflammatory cells infiltration, (3) The space between the cells becoming wider, (4) Epithelial cell sloughing off can be found in SM group.

Genome-wide DNA methylation profiles of the $S$.

aureus infected mice and non-infected controls

Genome-wide DNA methylation profiles of the two groups were generated using the F-MSAP method. Eight pairs of selected primers were labeled with fluorescent dyes to detect DNA methylation patterns in udder tissue of the two groups. The fragments between $100 \mathrm{bp}$ and $500 \mathrm{bp}$ were highly intense. $\mathrm{Cl}$ (the first sample of $\mathrm{C}$ group) showed inner methylated of double stranded DNA and SM1 (the first sample of SM group) showed outer methylated of double stranded DNA (Figure 3A). The F-MSAP fragment gel files (Figure 3A) were captured by DNA sequencer and transferred into signal peaks (Figure 3B) and data (Figure 3C) through GeneMarker V1.65 software. A total of 369 clear bands were amplified from udder tissue samples of the two groups as shown in Figure 3D, and the bands in the red frame were the differentially methylated fragments.

DNA methylation levels of the two groups

Methylation levels of the two groups were detected according to the bands of four FAM-labeled primers. The analysis of variance and Duncan's multiple range tests were performed to evaluate the different methylation levels of the two groups. Variances of four DNA methylation patterns between two groups are shown in Supplementary Table S1. In the S. aureusinfected mouse group, the type I bands (un-methylated) are much lower than those in the control group $(\mathrm{p}<0.01)$. As for whole methylation bands (II+III+IV [\%]) and full methylation bands (II+IV [\%]), there were also significant differences between the two groups with $\mathrm{p}<0.01$ and $\mathrm{p}<0.05$, respectively (Figure 3E). These findings indicated that DNA methylation level in S. aureus-infected mice was significantly increased. 
A

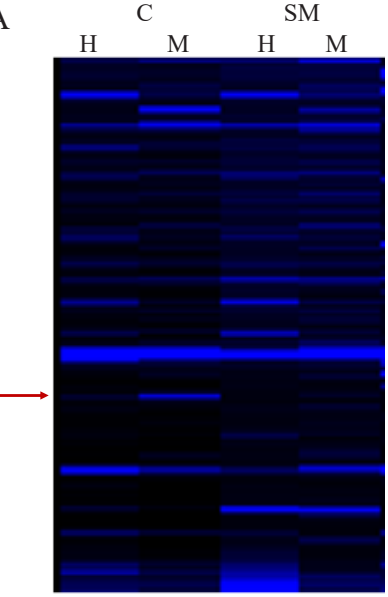

B

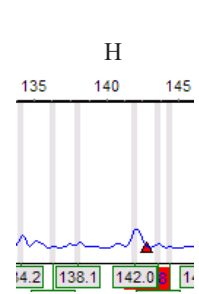

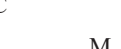

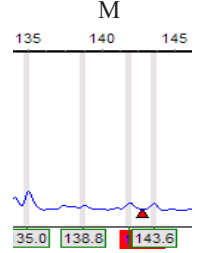

SM

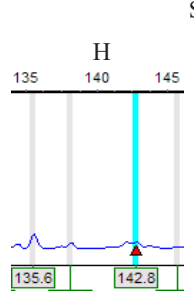

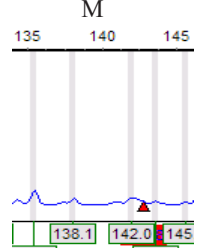

$\mathrm{C}$

\begin{tabular}{|c|c|c|c|c|}
\multicolumn{2}{|c|}{ Fragment length (bp) } & 136.4 & 142.8 & 144.4 \\
\hline C & H & 1 & 0 & 1 \\
\hline \multirow{3}{*}{ SM } & M & 0 & 1 & 0 \\
& $\mathrm{H}$ & 0 & 0 & 0 \\
\hline & $\mathrm{M}$ & 0 & 0 & 0 \\
\hline
\end{tabular}

$\mathrm{D}$

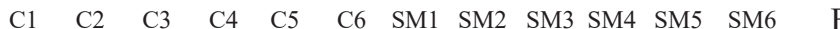
H M H M M H M H M M H M H M M H M M H M

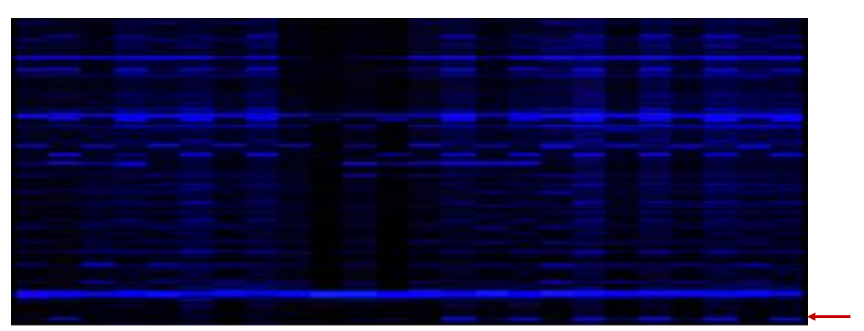

E

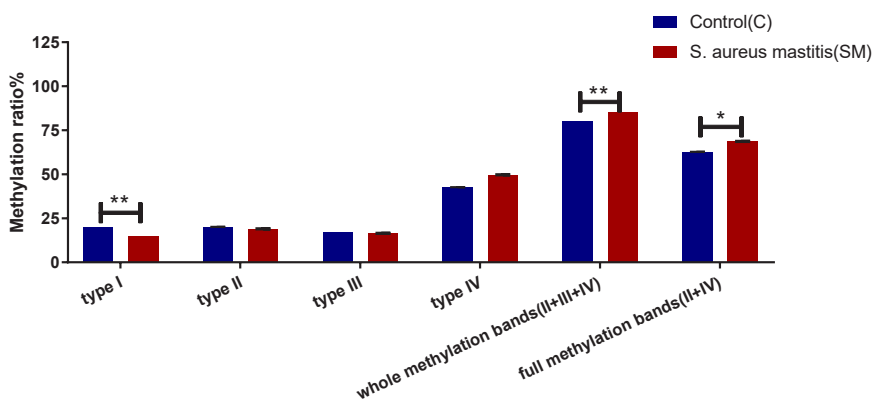

Figure 3. The electrophoresis and illustration of selective amplification. (A-C) An example showing how the signals in F-MSAP were named; (A) C: control group; SM: Staphylococcus aureus (S. aureus) induced mastitis group; Line M: a system of EcoR I/Msp I; line H: a system of EcoR I/Hpa II; (B) The signal peak represents methylationsensitive amplified polymorphic fragments labeled with FAM fluorescent dye; the height of the peak represents the molecular weight of the fragments; (C) $1=$ band, $0=$ no band. (D) The fluorescent electrophoresis of the fourth primer of the 12 samples. C1-C6 are six replicates of control group; SM1-SM6 are six replicates of S. aureus induced mastitis group; Line M: a system of EcoR I/Msp I; line H: a system of EcoR I/Hpa II; red arrow indicated the different band pattern between the two groups. (E) DNA methylation levels of the four primers of the two groups. Whole methylation represents the sum of type II, type III, and type IV; full methylation represents the sum of type II and type IV.

\section{S. aureus-induced changes in the differentially} methylated bands in mouse udder tissue

All possible banding patterns between S. aureus-infected mastitis mice and healthy controls were explored to identify the changes in cytosine methylation patterns. Differentially methylated bands refer to the differences between the bands of $\mathrm{M}$ and $\mathrm{H}$ lanes in two experimental groups. The different DNA methylation patterns of the four FAM-labeled primers in the control group and SM group are shown in Supplementary Table S2. Out of 29 bands, three were highly significantly different, 25 bands showed significant differences and only one band remained unchanged under $S$. aureus-induced events between the two groups. These findings indicated there are frequent DNA methylation events when $S$. aureus attack udder tissue. The analysis of significantly differential methylated bands between two groups was carried out using $t$-test in EXCEL.

Differentially methylated genes between S. aureus- induced mastitis mice and healthy controls

To identify the differentially methylated genes, a total of 20 bands were excised from polyacrylamide gels after silver staining, followed secondary PCR and sequencing. Two differentially methylated fragments (100 to $200 \mathrm{bp}$ ) with different methylation patterns were confirmed as gene NCK-associated protein 5 (Nckap5) (150 bp) and transposon MTD (116 bp) through sequencing alignment (http://genome.ucsc.edu/ cgi-bin/hgBlat) (Sequencing alignment results are shown in Supplementary Figure S2, S3). Nckap5 is related to the promotion of the cell death [20], which should be methylated under normal conditions. In current results, Nckap5 is hypo-methylated in S. aureus mastitis mice (Figure 4A). In SM group, except for SM1 showing type III (semi-methylated), other samples all showed type I (un-methylated); while in C group, except for C3 showed type I, others showed type II (inner methylated of double stranded sequence). Transposon MTD showed lower methylation level in S. aureus mastitis group compared with control group. In SM group, 
A

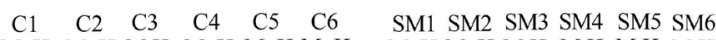
$150 \mathrm{bp} \longrightarrow \mathrm{M} \mathrm{H} \mathrm{M} \mathrm{MH} \mathrm{M} \mathrm{M} \mathrm{M} \mathrm{M} \mathrm{H} \mathrm{M} \mathrm{M} \mathrm{M} \mathrm{M} \mathrm{MH} \mathrm{MH} \mathrm{MH}$

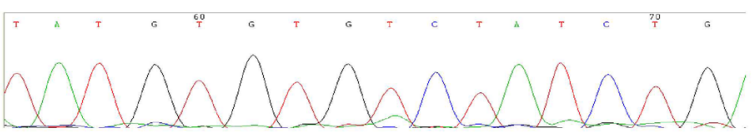
C
B

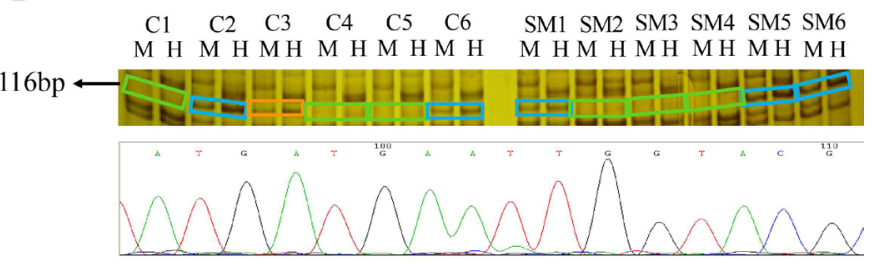

S. aureus-induced mastitis

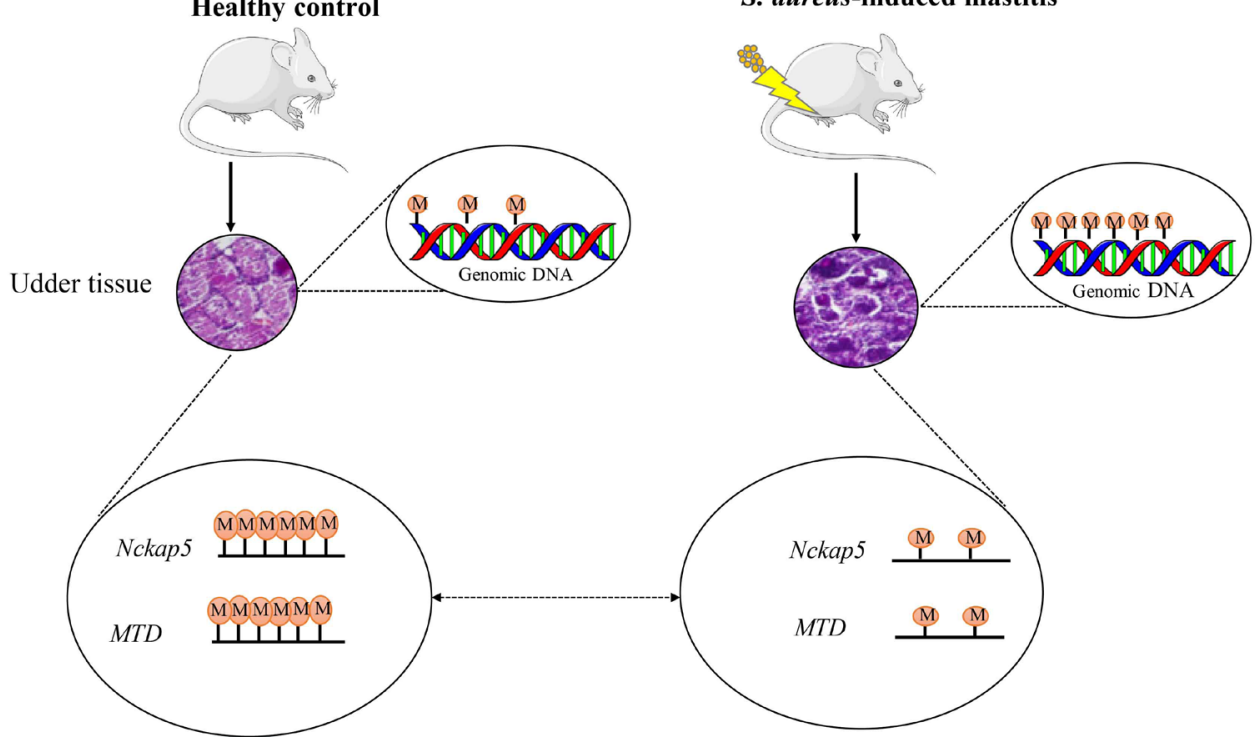

Figure 4. Silver staining and sequencing results of two differentially methylated fragments between SM mice group and controls. (A) Silver staining and partial sequencing result of gene NCK-associated protein 5 (Nckap5); C1-C6 are six replicates of control group; SM1-SM6 are six replicates of Staphylococcus aureus (S. aureus) induced mastitis group; Line M: a system of EcoR I/Msp I, line $\mathrm{H}$ : a system of $E c 0 R$ I/Hpa II. Different color of the frames represents different DNA methylation pattern: light blue = Type I; wine red = Type II. (B) Silver staining and partial sequencing results of transposon MTD; C1-C6 are six replicates of control group; SM1-SM6 are six replicates of S. aureus induced mastitis group; Line M: a system of EcoR I/Msp I, line H: a system of EcoR I/Hpa II. Different color of the frames represents different DNA methylation pattern: light blue = Type l; orange = Type III; light green = Type IV. (C) The genome-wide DNA methylation level of S. aureus-induced mastitis mice is higher than that in healthy controls, gene Nckap5 and transposon MTD showed hypo-methylation in S. aureus mastitis group. The circles with letter M inside indicates methylation, and the number of circles represents level of methylation.

SM1, SM5, and SM6 showed type I (un-methylated) and SM2, SM3, and SM4 showed type IV (outer methylated of double stranded); while in $\mathrm{C}$ group, $\mathrm{C} 1, \mathrm{C} 4$, and $\mathrm{C} 5$ showed type IV (outer methylated of double stranded); C2 and C6 showed type I (un-methylated) and C3 showed type III (semimethylated) (Figure 4B). Since Nckap5 gene and transposon MTD were found to be hypo-methylated in S. aureus infected mouse udder tissue, we assumed that these two genes might trigger inflammatory changes in udder tissue (Figure $4 \mathrm{C})$.

\section{DISCUSSION}

The current study used a mouse model to evaluate the changes of genome-wide DNA methylation patterns and levels in udder tissues post $S$. aureus infection. Two differentially methylated genes (Nckap5 and transposon MTD) were discovered which could be indicators of $S$. aureus mastitis.

Mice can serve as an appropriate research model for bovine mastitis study due to their low cost and ease of maintenance [21]. Here, a S. aureus-infected mouse model was established and optimized, which is the pre-requisite for obtaining reliable results. Fan et al [22] had evaluated the body temperature, udder tissue slices, milk white cell count, $\mathrm{CBC}$ and $\mathrm{CD} 4^{+} /$ $\mathrm{CD}^{+}$ratio pre- and post-challenge in order to establish the S. aureus mouse model, which is consistent with the present study. These observations suggest that our established S. aureus mouse model showed consistency and reliability for the further experimental procedure.

In the current study, we used F-MSAP method to detect genomic DNA methylation variance of udder tissues between S. aureus-induced mastitis mice and healthy mice. F-MSAP assay is modified from MSAP, which using fluorescently labeled primers and capillary gel electrophoresis instead of traditional denaturing acrylamide gel electrophoresis and silver staining $[16,23,24]$. Compared with MASP, F-MASP method has been proven to be safer, more efficient and with higher resolution because it can automatically detect genome- 
wide DNA methylation patterns with DNA sequencer. Based on F-MASP analysis, our findings revealed that the genomic DNA methylation level of mastitis mice was significantly higher than those in healthy mice. Similarly, a higher methylation level was found in the lymphocytes of $S$. aureus mastitis cows compared with healthy cows [13]. Thus, the data suggest that the methylation level of $S$. aureus mastitis-related genes may be changed because of DNA methylation fluctuations in S. aureus infected mice.

Subsequently, two differentially methylated genes (Nckap5 and transposon MTD) in mouse udder tissue were obtained, which may have important roles in the development or resistance of $S$. aureus mastitis. Our findings revealed hypomethylation of Nckap5 in S. aureus-induced mastitis mice. In a previous study, it was cited that human NCKAP5 gene encodes Nck-associated protein 5 and the Nck protein reportedly plays a role in the process of the Fas ligand (FasL) factorinduced cell death [20]. These indicated that the Nckap5 gene might have a role in promoting the death of immune cells. A genome-wide association study revealed that a polymorphism near NCKAP5 showed significant link with symptoms of depression in humans [25]. A recent study reported that structural variations in cell line MHH-CALL-2 include homozygous inversion (NCKAP5) are responsible for disturbance of epigenetic gene regulation in childhood acute lymphoblastic leukemia by using next generation sequencing [26]. Moreover, in our results, we noted a higher level of methylation of transposon MTD in the healthy control group compared to the mastitis group, which is consistent with a recently reported study that showed the transposon is under a state of hyper-methylation in healthy status [27]. Transposon MTD belongs to Family ERVL-MaLR (mammalian apparent long terminal repeat [LTR] retrotransposons), which is mammalian apparent LTR-retrotransposons, which shows a lower expression in early embryos than other retrotransposons [28]. Studies suggested that DNA methylation status of the CACTA transposon can explain the incomplete penetrance and poor expressivity of the maize (Zea mays) mutant unstable factor for orange1 (Ufo1) [29]. Hypomethylation of Karma transposon is associated with the mantled phenotype in oil palm [30]. In aggregate, the data obtained in current research and the previously reported studies infer the importance of Nckap5 and transposon MTD as indicators and they might be targets in remedies of mastitis. Further biological investigation is needed to validate the reliability of the current findings through pyro-sequencing and the gene expression via quantitative real-time PCR; in addition, the regulatory mechanisms of methylation changes could be study in mammary gland of dairy cow infected by S. aureus.

In conclusion, these findings offered a base line understanding of the investigation of dairy cow mastitis infected by $S$. aureus and provided a comprehensive picture of DNA methylation in S. aureus infected udder tissue. In addition, we suggested that the DNA methylation variation of Nckap5 and transposon MTD might be considered as indicators and methylation markers in a control strategy of $S$. aureus mastitis, and provided a new insight into $S$. aureus mastitis research in dairy industry and public health.

\section{CONFLICT OF INTEREST}

We certify that there is no conflict of interest with any financial organization regarding the material discussed in the manuscript.

\section{ACKNOWLEDGMENTS}

This research was financially supported by the Beijing Natural Science Foundation (6182021), Beijing Dairy Industry Innovation Team (BAIC06), National Natural Science Foundation of China (31272420), Modern Agro-industry Technology Research System (CARS-36) and the Program for Changiiang Scholar and Innovation Research Team in University (IRT15R62).

\section{REFERENCES}

1. Bradley AJ. Bovine mastitis: an evolving disease. Vet J 2002; 164:116-28. https://doi.org/10.1053/tvjl.2002.0724

2. Viguier C, Arora S, Gilmartin N, Welbeck K, O'Kennedy R. Mastitis detection: current trends and future perspectives. Trends Biotechnol 2009;27:486-93. https://doi.org/10.1016/ j.tibtech.2009.05.004

3. Hagnestam-Nielsen C, Emanuelson U, Berglund B, Strandberg E. Relationship between somatic cell count and milk yield in different stages of lactation. J Dairy Sci 2009;92:3124-33. https://doi.org/10.3168/jds.2008-1719

4. Sordillo LM, Streicher KL. Mammary gland immunity and mastitis susceptibility. J Mammary Gland Biol Neoplasia 2002; 7:135-46.

5. Donovan DV, Kerr DE, Wall RJ. Engineering disease resistant cattle. Transgenic Res 2005;14:563-7. https://doi.org/10.1007/ s11248-005-0670-8

6. Sharma N, Singh NK, Bhadwal MS. Relationship of somatic cell count and mastitis: an overview. Asian-Australas J Anim Sci 2011;24:429-38. https://doi.org/10.5713/ajas.2011.10233

7. Sears PM, McCarthy KK. Management and treatment of staphylococcal mastitis. Vet Clin North Am Food Anim Pract 2003;19:171-85. https://doi.org/10.1016/S0749-0720 (02)00079-8

8. Zilberman D, Henikoff S. Genome-wide analysis of DNA methylation patterns. Development 2007;134:3959-65. https:// doi.org/10.1242/dev.001131

9. Whayne TF. Epigenetics in the development, modification, 
and prevention of cardiovascular disease. Mol Biol Rep 2015; 42:765-76. https://doi.org/10.1007/s11033-014-3727-z

10. Ogorevc J, Kunej T, Razpet A, Dovc P. Database of cattle candidate genes and genetic markers for milk production and mastitis. Anim Genet 2009;40:832-51. https://doi.org/10.1111/ j.1365-2052.2009.01921.x

11. Wang XS, Zhang Y, He YH, et al. Aberrant promoter methylation of the $\mathrm{CD} 4$ gene in peripheral blood cells of mastitic dairy cows. Genet Mol Res 2013;12:6228-39. https:/doi.org/ 10.4238/2013.December.4.10

12. Chang G, Petzl W, Vanselow J, Günther J, Shen X, Seyfert HM. Epigenetic mechanisms contribute to enhanced expression of immune response genes in the liver of cows after experimentally induced Escherichia coli mastitis. Vet J 2015;203: 339-41. https://doi.org/10.1016/j.tvjl.2014.12.023

13. Song MY, He YH, Zhou HK, Zhang Y, Yu Y. Combined analysis of DNA methylome and transcriptome reveal novel candidate genes with susceptibility to bovine Staphylococcus aureus subclinical mastitis. Sci Rep 2016;6:29390. https://doi.org/10.1038/ srep29390

14. Breyne K, Honaker RW, Hobbs Z, et al. Efficacy and safety of a bovine-associated Staphylococcus aureus phage cocktail in a murine model of mastitis. Front Microbiol 2017;8:2348. https://doi.org/10.3389/fmicb.2017.02348

15. Guevara MÁ, de María N, Sáez-Laguna E, Vélez MD, Cervera MT, Cabezas JA. Analysis of DNA cytosine methylation patterns using methylation-sensitive amplification polymorphism (MSAP). In: Kovalchuk I, editor. Plant Epigenetics. Methods in Molecular Biology. Boston, MA, USA: Humana Press; 2017. vol 1456. pp. 99-112. https://doi.org/10.1007/9781-4899-7708-3_9

16. Xu Q, Sun D, Zhang Y. F-MSAP: A practical system to detect methylation in chicken genome. Chin Sci Bull 2005;50:203944. https://doi.org/10.1007/BF03322798

17. National Mastitis Council. Laboratory handbook on bovine mastitis. Nat Mastitis Council; 1999.

18. Gao J, Ferreri M, Liu XQ, Chen LB, Su JL, Han B. Development of multiplex polymerase chain reaction assay for rapid detection of Staphylococcus aureus and selected antibiotic resistance genes in bovine mastitic milk samples. J Vet Diagn Invest 2011;23:894-901. https://doi.org/10.1177/10406387 11416964

19. Brakstad OG, Aasbakk K, Maeland JA. Detection of Staphylococcus aureus by polymerase chain reaction amplification of the nuc gene. J Clin Microbiol 1992;30:1654-60.
20. Lettau M, Qian J, Linkermann A, Latreille M, Larose L, Kabelitz D, et al. The adaptor protein Nck interacts with Fas ligand: Guiding the death factor to the cytotoxic immunological synapse. Proc Natl Acad Sci USA 2006;103:5911-6. https:// doi.org/10.1073/pnas.0508562103

21. Brouillette E, Malouin F. The pathogenesis and control of Staphylococcus aureus-induced mastitis: study models in the mouse. Microbes Infect 2005;7:560-8. https://doi.org/10.1016/ j.micinf.2004.11.008

22. Fan LJ, Zhang MZ, Wei YY, et al. Establishment of mice models of staphylococcus aureus of dairy cows mastitis. Laboratory Anim Sci 2011;28:1-6.

23. Vos P, Hogers R, Bleeker M, et al. AFLP: a new technique for DNA fingerprinting. Nucleic Acids Res 1995;23:4407-14. https://doi.org/10.1093/nar/23.21.4407

24. Huang J, Sun M. A modified AFLP with fluorescence-labelled primers and automated DNA sequencer detection for efficient fingerprinting analysis in plants. Biotechnol Tech 1999;13: 277-8. https://doi.org/10.1023/A:1008970618252

25. Luciano M, Huffman JE, Arias-Vásquez A, et al. Genomewide association uncovers shared genetic effects among personality traits and mood states. Am J Med Genet B Neuropsychiatr Genet 2016;159B:684-95. https://doi.org/10.1002/ ajmg.b.32072

26. Chen C, Bartenhagen C, Gombert M, et al. Next-generationsequencing-based risk stratification and identification of new genes involved in structural and sequence variations in near haploid lymphoblastic leukemia. Genes Chromosomes Cancer 2013;52:564-79. https://doi.org/10.1002/gcc.22054

27. Yu Y, Zhang H, Tian F, et al. Quantitative evaluation of DNA methylation patterns for $A L V E$ and TVB genes in a neoplastic disease susceptible and resistant chicken model. PloS One 2008;3:e1731. https://doi.org/10.1371/journal.pone.0001731

28. Eymery A, Liu Z, Ozonov EA, Stadler MB, Peters AH. The methyltransferase Setdb1 is essential for meiosis and mitosis in mouse oocytes and early embryos. Development 2016;143: 2767-79. https://doi.org/10.1242/dev.132746

29. Sekhon RS, Peterson T, Chopra S. Epigenetic modifications of distinct sequences of the $p 1$ regulatory gene specify tissuespecific expression patterns in maize. Genetics 2007;175:105970. https://doi.org/10.1534/genetics.106.066134

30. Ong-Abdullah M, Ordway JM, Jiang N, et al. Loss of Karma transposon methylation underlies the mantled somaclonal variant of oil palm. Nature 2015;525:533-7. https://doi.org/ 10.1038/nature15365 